\title{
Ultrasonic Disintegration of Bacteria Contained in Treated Wastewater
}

\section{Eliza Hawrylik'}

1 Department of Chemistry, Biology and Biotechnology, Faculty of Civil and Environmental Engineering, Bialystok University of Technology, Wiejska 45E, 15-351 Bialystok, Poland

e-mail: e.hawrylik@doktoranci.pb.edu.pl

\begin{abstract}
The amount of wastewater discharged in Poland is constantly increasing. Although wastewater is subjected to purification processes, it constitutes the habitat of many microorganisms, including pathogenic bacteria, which infiltrate into the environment and may pose a biological threat. The purpose of this paper was to explore the possibility of using a low-frequency ultrasound to disintegrate the microorganisms found in the treated wastewater. The paper presents the research on the use of ultrasound with a frequency of 20 and $40 \mathrm{kHz}$, with variable and constant operation mode of an ultrasonic cleaner, to destroy the bacteria of the Sarcina genus. The results obtained indicate the effective action of ultrasonic waves in relation to the microorganisms studied. Already a 5-minute exposure to ultrasound at a frequency of $20 \mathrm{kHz}$ with a continuous operation mode of the device reduced the number of bacteria by over $60 \%$. The 30 -minute operation of $40 \mathrm{kHz}$ ultrasonic waves resulted in $80 \%$ decrease in the number of microorganisms, compared to the control. The obtained results prove the possibility of using the ultrasonic disintegration process in municipal wastewater treatment plants.
\end{abstract}

Keywords: disintegration, ultrasounds, bacteria, treated wastewater

\section{INTRODUCTION}

The total amount of sewage discharged in Poland is constantly increasing. According to the data from the Statistics Poland, 1254372.5 dam $^{3}$ of sewage was discharged in 2008, and even 1330 274.7 dam $^{3}$ in 2018 [Statistics Poland 2019]. The Polish legislation regulates a number of issues related to the proper functioning of water supply and sewage disposal companies. Act of June 7, 2001 on collective water supply and collective sewage disposal (Journal of Laws of 2018, item 1152) and Regulation of the Minister of Maritime Economy and Inland Navigation of July 12, 2019 on particularly harmful substances for the aquatic environment and the conditions to be met when discharging sewage into waters or into the ground, as well as when discharging rainwater or snowmelt into waters or water facilities (Journal of Laws 2019, item 1311), impose the requirements upon wastewater treatment plants related to the quality of treated wastewater; however, they mainly concern the physicochemical parameters. In terms of microbiological conditions, only in the case of the wastewater intended for agricultural use, the afore-mentioned legal acts impose the obligation to determine if there are Salmonella and intestinal parasitic eggs belonging to Ascaris sp., Trichuris $s p$., or Toxocara sp. in the wastewater. No water or soil requirements are imposed.

Wastewater, as it is commonly known, is the habitat of many microorganisms, including pathogenic bacteria. Their number is subject to significant changes over time, and depends primarily on the composition of raw sewage flowing into the treatment plant. Wastewater allows microorganisms to infiltrate into other environments, i.e. soil or water of the receiver, causing a biological threat of varying severity [Butarewicz 2012, Butarewicz 2016]. According to the American Environmental Protection Agency, the average bacterial survival in the soil or plant surface varies from one month to two months, and their maximum life is one year [US EPA 2003]. 
The wastewater subjected to the treatment process in wastewater treatment plants is considered to be treated wastewater. It contains a number of organic and inorganic substances and in some cases may contain potentially toxic elements such as: $\mathrm{As}, \mathrm{Cd}, \mathrm{Cr}, \mathrm{Cu}, \mathrm{Pb}, \mathrm{Hg}, \mathrm{Zn}$. Their low concentrations can have an effect on the phytotoxic level, without creating a risk to humans. However, from the point of view of human health, pathogenic microorganisms and macroorganisms, especially in the agricultural use of sewage, are the most worrying [Sperling 2007].

The majority of known and used wastewater treatment technologies, although cleanse wastewater from chemicals well, does not give $100 \%$ certainty that the treated wastewater will be completely safe in sanitary and chemical terms. The survival of microorganisms is a function of many factors, which include, among others, ambient temperature, antagonistic factors prevailing in a given environment, or individual characteristics of strains belonging to a given species. Typical wastewater treatment processes ensure a high level of bacterial reduction, up to $99 \%$. Despite such high efficiency of bacteria removal from wastewater, it still contains, among others, the coliforms in the range from $10^{4}$ to $10^{6} / 100 \mathrm{ml}$ [Michałkiewicz et al. 2011, Butarewicz 2013].

Due to the lack of legal provisions requiring obligatory testing of sewage in sanitary and microbiological terms in Poland, this type of analysis is rarely performed (they are only necessary if the sewage is intended for agricultural use). According to the research carried out by Butarewicz [2016], the sanitary properties of raw sewage did not differ from the average values typical for the municipal sewage. The average effectiveness of removing the total number of bacteria in the wastewater treatment process ranged from $87-94 \%$, while the number of coliform bacteria decreased by 93.3-97.7\% [Butarewicz 2016].

Increasing the level of sanitary safety of municipal sewage treatment plants requires disinfection of the treated sewage. Numerous methods used to destroy microorganisms affect the vegetative cells and spore forms in various ways. Viruses react differently to the disinfection process, bacteria and fungi react differently, and parasitic protists and worms in a different way. Common disinfection of wastewater and by-products that arise during the treatment processes can be carried out with physical and chemical methods [Kaźmierczuk and Kalisz 2011]. In the case of highly infectious sewage, thermal disinfection is necessary. In addition, it should be remembered that chlorine does not eliminate some pathogens, cysts and oocysts of parasitic protozoa. Therefore, other effective solutions which include modern membrane techniques [Bodzek et al. 2019] and low frequency ultrasounds [Butarewicz 2012] should be sought. Ultrasounds are increasingly used for the destruction of pathogenic microorganisms in the process of ultrasonic hygienization of sewage sludge [Hawrylik 2018]; therefore, it was decided to conduct experiments using lowfrequency ultrasound in the disintegration of bacteria present in the treated wastewater.

\section{MATERIALS AND METHODS}

The study on the influence of low-frequency ultrasound on the disintegration of microorganisms contained in ultrapure water was carried out at the turn of January and February 2019 in the microbiological laboratory of the Department of Chemistry, Biology and Biotechnology of the Faculty of Civil Engineering and Environmental Engineering at Białystok University of Technology.

The experiments were carried out to determine the effect of ultrasounds at 20 and $40 \mathrm{kHz}$ on the survival of Sarcina bacteria inoculated in ultrapure water that was considered an equivalent of purified wastewater. The studies used the reference microbial species from the ATCC collection (American Type Culture Collection), while the Polsonic ultrasonic washers for the ultrasound 20 and $40 \mathrm{kHz}$ were used for disintegration.

In the first stage of the experiments, bacteria were cultured on the broth medium for propagation. The samples were incubated in an incubator at $37^{\circ} \mathrm{C}$ for 24 hours. After the incubation of bacteria, $30 \mathrm{~cm}^{3}$ of broth bacterial culture was added to $3 \mathrm{dm}^{3}$ of ultra-pure water and placed in a Polsonic ultrasonic cleaner that generated ultrasound at a frequency of $20 \mathrm{kHz}$. The tests were carried out with continuous and pulsatory mode of the device operation. An analogous process was carried out in a second washer generating ultrasounds with a frequency of $40 \mathrm{kHz}$ in continuous operation mode. The samples were sonicated for 30 minutes.

Before proceeding with the disintegration, the number of Sarcina bacteria was determined in a control test (not subject to ultrasound). For 
this purpose, $1 \mathrm{~cm}^{3}$ of the test medium was taken and serial dilutions in the range from $10^{-1}$ to $10^{-6}$ were prepared, transferring the collected volume into tubes containing $9 \mathrm{~cm}^{3}$ of physiological fluid. Subsequently, the test sample was sonicated. After $5,10,15,20,25$ and 30 minutes, $1 \mathrm{~cm}^{3}$ of the mixture was taken, followed by dilutions identical to those of the reference sample. In a further stage of the research, the samples were plated on agar plates ranging from $10^{-1}$ to $10^{-6}$. In order to determine the number of bacteria, the plates were incubated in an incubator at $37^{\circ} \mathrm{C}$ for 24 hours. After incubation, the number of colony forming units (CFUs) grown on the plates was determined. Only the tiles with 10 to 150 colonies were considered. On the basis of the obtained results, average values in $\mathrm{cfu} / \mathrm{cm}^{3}$ were calculated.

In the experiments conducted, the number of bacteria in the reference sample as well as in the samples subjected to sonication was calculated based on the formula:

$$
N=\frac{A}{R}
$$

where: $N$-number of cfu in $1 \mathrm{~cm}^{3}$,

$A$ - number of decks grown on the plate,

$R$ - sample dilution.

\section{RESEARCH RESULTS AND DISCUSSION}

The diversity of microorganisms contained in the treated wastewater is quite significant, and the greatest threat is associated with the occurrence of, among others, pathogenic bacteria. Despite the fact that Escherichia coli is one of the basic indicators of the sanitary quality of water, wastewater and sewage sludge [Naidoo and Olaniran 2014], the selection of Sarcina microorganisms for research was not accidental. The most pathogenic bacteria originate from humans and warmblooded animals, and their natural temperature is around $37{ }^{\circ}$ C. Sarcina bacteria are mesophilic, Gram-positive cocci, forming clusters, related to the type of Clostridium. The species associated with human infection are Sarcina ventriculi and Sarcina maxima. They are most commonly found in the patients with gastrointestinal disorders [Elvert et al. 2018]. The reason for the application of ultrapure water resulted from the previous microbiological tests indicating a small number of these bacteria in the treated wastewater. Additional presence of other microbial species could adversely affect the result of the experiment $[\mathrm{Bu}-$ tarewicz 2016].

Table 1 lists the changes in the number of Sarcina bacteria in ultrapure water subjected to ultrasound at 20 and $40 \mathrm{kHz}$ with the temperature increase recorded during the process, while Figure 1 shows the percentage changes in the number of microorganisms depending on the time of sonication.

On the basis of the obtained results, a significant reduction in the number of Sarcina bacteria inoculated into ultrapure water was found.

Just after 5 minutes of sonication at $20 \mathrm{kHz}$ with constant operation mode, a decrease in the number of microorganisms by $62.22 \%$ was noted, with a slight increase in temperature - by about $2{ }^{\circ} \mathrm{C}$. Along with the extension of the ultrasound process duration, the number of bacteria decreased, reaching efficiency of almost $98 \%$ after 10 minutes of the process. The temperature range during the measurements reached a maximum of $33^{\circ} \mathrm{C}$, with an initial value of $20^{\circ} \mathrm{C}$.

The operation of ultrasounds with a frequency of $20 \mathrm{kHz}$ in the pulsed mode of the device operation resulted in a much weaker disintegration

Table 1. Changes in the number of Sarcina bacteria treated with ultrasound alon with the temperature increase observed during the sonication process

\begin{tabular}{|c|c|c|c|c|c|c|}
\hline \multirow{2}{*}{$\begin{array}{c}\text { Time of } \\
\text { sonication } \\
{[\mathrm{min}]}\end{array}$} & \multicolumn{2}{|c|}{$20 \mathrm{kHz}-$ continuous work } & \multicolumn{2}{|c|}{$20 \mathrm{kHz}-$ pulsating work } & \multicolumn{2}{c|}{$40 \mathrm{kHz}$} \\
\cline { 2 - 7 } & $\begin{array}{c}\text { Sarcina }[\mathrm{cfu} / \\
\left.\mathrm{cm}^{3}\right]\end{array}$ & $\begin{array}{c}\text { Temperature } \\
{\left[{ }^{\circ} \mathrm{C}\right]}\end{array}$ & $\begin{array}{c}\text { Sarcina }[\mathrm{cfu} / \\
\left.\mathrm{cm}^{3}\right]\end{array}$ & $\begin{array}{c}\text { Temperature } \\
{\left[{ }^{\circ} \mathrm{C}\right]}\end{array}$ & $\begin{array}{c}\text { Sarcina [cfu/ } \\
\left.\mathrm{cm}^{3}\right]\end{array}$ & $\begin{array}{c}\text { Temperature } \\
{\left[{ }^{\circ} \mathrm{C}\right]}\end{array}$ \\
\hline 0 & $4.50^{*} 10^{6}$ & 20 & $7.20^{*} 10^{5}$ & 21 & $6.70^{*} 10^{4}$ & 29 \\
\hline 5 & $1.70^{*} 10^{6}$ & 22 & $6.20^{*} 10^{5}$ & 22 & $5.90^{*} 10^{4}$ & 31 \\
\hline 10 & $1.10^{*} 10^{5}$ & 25 & $5.20^{*} 10^{5}$ & 24 & $4.80^{*} 10^{4}$ & 33 \\
\hline 15 & $0.80^{*} 10^{5}$ & 27 & $4.80^{*} 10^{5}$ & 25 & $3.90^{*} 10^{4}$ & 33 \\
\hline 20 & $0.60^{*} 10^{5}$ & 29 & $4.20^{*} 10^{5}$ & 26 & $3.50^{*} 10^{4}$ & 35 \\
\hline 25 & $0.54^{*} 10^{5}$ & 31 & $4.00^{*} 10^{5}$ & 27 & $2.50^{*} 10^{4}$ & 35 \\
\hline 30 & $0.13^{*} 10^{5}$ & 33 & $3.80^{*} 10^{5}$ & 29 & $1.30^{*} 10^{4}$ & 38 \\
\hline
\end{tabular}




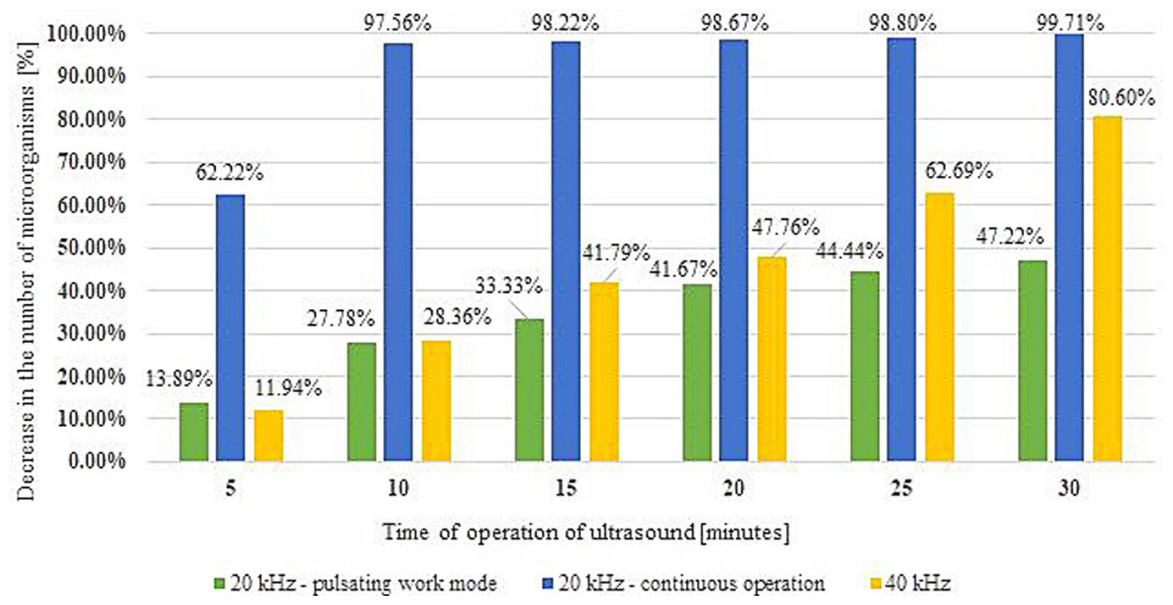

Fig. 1. Percentage changes in the number of Sarcina bacteria subjected to ultrasound

effect than in the case of continuous work. After 5 minutes of the process, the number of microorganisms decreased by only $13.89 \%$, whereas after 15 minutes it was $33.33 \%$ and after 30 minutes $47.22 \%$. During the whole process, the temperature increased by $6{ }^{\circ} \mathrm{C}\left(21-27^{\circ} \mathrm{C}\right)$.

The operation of the ultrasonic cleaner with the frequency of wave generation at the level of $40 \mathrm{kHz}$ (continuous ultrasonic waves) caused the suppression of microbial growth in ultrapure water to be higher than in the case of ultrasonic cleaner with the frequency of generating waves at $20 \mathrm{kHz}$ in continuous mode of operation. After 15 minutes of the sonification process, there was a decrease of $41.79 \%$, after 25 minutes $62.69 \%$, and after 30 minutes, the number of bacteria decreased by $80.60 \%$ compared to the reference sample. The temperature increased by $9{ }^{\circ} \mathrm{C}$, reaching a maximum of $38^{\circ} \mathrm{C}$.

The overall temperature increase during all the tested variants of the sonification process was small; thus, it can be assumed that the temperature achieved in the experiment did not have a major impact on the microbial destruction process.

The literature is increasingly considering the issue of ultrasonic disintegration, but a small number of items address the problem of ultrasonic destruction of bacteria present in wastewater. Similar to the present study, the results were obtained by Bień et al. [1995], who applied Escherichia coli to the water. The action of ultrasound with a frequency of $21 \mathrm{kHz}$ caused the effectiveness of these microorganisms destruction in the range of $0 \%$ to $90 \%$. Foladori et al. [2007] showed high sensitivity of $E$. coli to sonication at $20 \mathrm{kHz}$. Butarewicz [2016] indicated a reduction in the number of $E$. coli in the treated wastewater.
In addition, he proved the effect of low frequency ultrasounds on the destruction of selected microorganisms belonging to the group of indicator bacteria (Enterococcus faecalis, Salmonella enteritidis and Bacillus subtilis) present in the purified wastewater. Unfortunately, there are no references in the literature regarding the impact of low frequency ultrasounds on the destruction of Sarcina bacteria.

It should be noted that the research on ultrasonic disintegration is mainly related to sewage sludge. A significant part of the work deals with the problem of sonication and subsequent use of sewage sludge in the fermentation process. The sludge subjected to ultrasonic disintegration is more susceptible to fermentation, the effects of which are: increasing the production of biogas, which is a carrier of renewable energy, and reducing the amount of digested sludge [Simonetti et al. 2014, Bragugia et al. 2015, Skarżyński and Bartkowska 2018]. Ultrasonic disintegration is also used in improving the sanitary quality of sewage sludge. Rusin and Machnicka [2011] proved the action of ultrasound at the frequency of 25 and $40 \mathrm{kHz}$ for the reduction of the number of bacteria belonging to the Enterobacteriaceae family and pathogenic microorganisms of the genus Staphylococcus. Nowak [2015] and Hawrylik et al. [2017] indicated the possibility of using ultrasound at 22 and $40 \mathrm{kHz}$ frequency in relation to the Enterococcus faecalis bacteria. In the studies conducted by Butarewicz et al. [2017] and Hawrylik [2018], the effect of low frequency ultrasound on reducing the number of filamentous bacteria present in the activated sludge was found. The decomposition of activated sludge flocs was proven by Wu et al. [2018]. 
The presented results show the effectiveness of low frequency ultrasound on the destruction of microorganisms present in ultrapure water, being the equivalent of purified sewage. Ultrasonic disintegration can be used in municipal wastewater treatment plants. The use of ultrasounds for wastewater disinfection may contribute to the improvement of sanitary safety of sewage discharged into waters or into the ground.

\section{CONCLUSIONS}

1. The conducted experiments showed the effective operation of low-frequency ultrasounds $(20$ and $40 \mathrm{kHz})$ in the process of disintegration of Sarcina bacteria inoculated into ultra-pure water, which is the equivalent of treated sewage.

2. The operation of ultrasounds at $20 \mathrm{kHz}$, with the continuous mode of the ultrasound washer, caused more than $97 \%$ drop in the number of microorganisms after 10 minutes of the sonication process, while the pulsation mode of the device reduced the number of bacteria by about $28 \%$ at the same time.

3. The ultrasounds with the frequency of $40 \mathrm{kHz}$ caused a decrease in the number of microorganisms at a level close to $80 \%$ after 30-minute exposure time.

4. The best results among those tested in the scope of destruction of Sarcina bacteria were obtained by ultrasound at $20 \mathrm{kHz}$ with continuous operation of the ultrasonic cleaner.

5. Low frequency ultrasound should be used for the disintegration process in municipal wastewater treatment plants.

\section{Acknowledgements}

This work was carried out as part of the own work No. MB/WBiIŚ/3/2017, funded by the Ministry of Science and Higher Education.

\section{REFERENCES}

1. Act of June 7,2001 on collective water supply and collective sewage disposal (In Polish), (Journal of Laws of 2018, item 1152).

2. Bień J., Stępniak L., Palutkiewicz J. 1995. The effectiveness of water disinfection in the ultrasonic field. Environmental Protection (In Polish), 4: (59).
3. Bodzek M., Konieczny K., Rajca M. 2019. Membranes in water and wastewater disinfection - review. Archives on Environmental Protection, 1 (45): 3-18.

4. Butarewicz A. 2012. Why is it needed to implement disinfection of treated sewage? Gas, Water and Sanitary Technology (In Polish), 86 (6): 241-243.

5. Butarewicz A. 2012. Pathogenic organisms in sewage sludge - their detection and neutralization. Publishing House of the Białystok University of Technology (In Polish), Białystok.

6. Butarewicz A. 2016. Application of ultrasounds for the disintegration of microorganisms in sewage and sewage sludge. Publishing House of the Białystok University of Technology (In Polish), Białystok.

7. Butarewicz A., Wołejko E., Jabłońska-Trypuć A., Wydro U. 2017. The use of low frequency ultrasound to disintegrate filamentous bacteria. Engineering and Environmental Protection, 20 (3): 305-316.

8. Braguglia C. M., Gagliano M. C., Gallipoli A., Mannini G. 2015. The impact of sludge pretreatment for sludge anaerobic digestion: Effect of floc structure and microbial population, Bioresource Technology, 110: 43-49.

9. Elvert J. L., Atrouni W. E., Schuetz A. N. 2018. Answer to photo quiz: Sarcina ventriculi. Journal of Clinical Microbiology, 56 (12), 01335-17.

10. Foladori P., Laura B., Gianni A., Giulano Z. 2007. Effects of sonication on bacteria viability in wastewater treatment plants evaluated by flow cytometry-Fecal indicators, wastewater and activated sludge. Water research, 41 (1): 235-243.

11. Hawrylik E. 2018. Application of ultrasound in sludge treatment processes, Gas, Water and Sanitary Technology (In Polish), 5 (92): 187-189.

12. Hawrylik E. 2018. Influence of ultrasounds on the disintegration of filamentous bacteria present in activated sludge. Gas, Water and Sanitary Technology, 1(92): 29-31.

13. Hawrylik E., Zaręba K., Butarewicz A. 2017. Influence of ultrasounds on the survival of microorganisms present in sewage sludge. Environmental Engineer - Young Eye, Sewage and sewage sludge (In Polish), 31: 111-123.

14. Kaźmierczuk M., Kalisz L. 2011. Microbiological characteristics of municipal sewage and threats related to the presence of pathogenic microorganisms in them. Gas, Water and Sanitary Technology (In Polish), 4: 145-149.

15. Naidoo S., Olaniran A. 2014. Treated Wastewater Effluent as a Source of Microbial Pollution of Surface Water Resources. International Journal of Environmental Research and Public Health, 11(1): 249-270. 
16. Nowak D. 2015. Application of ultrasounds for sewage sludge decontamination, Engineering and Environmental Protection (In Polish), 18(4): 459-469.

17. Michałkiewicz M., Jeż-Walkowiak J., Dymaczewski Z., Sozański M. 2011. Wastewater disinfection. Journal of Ecological Engineering (In Polish), 24: $38-51$.

18. U.S. Environmental Protection Agency 2003. Environmental Regulations and Technology: Control of Pathogens and Vector Attraction in Sewage Sludge, Epa/625/R-92/013, Revised edition. U.S. EPA, Washington, D.C.

19. Regulation of the Minister of Maritime Economy and Inland Navigation from July 12, 2019 on substances particularly harmful to the aquatic environment and conditions to be met when introducing wastewater into the ground or into the ground, as well as when discharging rainwater or snowmelt into waters or equipment waters (In Polish), (Journal of Laws of 2019, item 1311).
20. Rusin A., Machnicka A. 2011. Ultrasonic cavitation in the hygienization of activated sludge). Scientific Works of GIG. Mining and Environment, Central Mining Institute (In Polish), 3: 73-80.

21. Simonetti M., Rossi G., Cabbai V., Goi D. 2014. Tests on the effect of ultrasonic treatment on two different activated sludge waste, Environment Protection Engineering, 40 (1): 23-34.

22. Skarżyński S., Bartkowska I. 2018. Ultrasounds in water, wastewater and sewage sludge management, Environmental Engineering - Young Eye, Ecoengineering, 37: 89-102.

23. Sperling von M. 2007. Wastewater characteristics, treatment and disposal. IWA Publishing, England, London.

24. Statistics Poland. 2019. Local Data Bank (In Polish). https://bdl.stat.gov.pl [Access: 24.07.2019].

25. Wu S., Zheng M., Dong Q., Liu Y., Wang C. 2018. Evaluating the excess sludge reduction in activated sludge system with ultrasonic treatment, Water Science and Technology, 77 (9): 2341-2347. 